\title{
El principio de autonomía en pediatría en el marco del nuevo Código Civil y Comercial de la Nación. Una comunicación de la Subcomisión de Ética Clínica
}

\author{
The principle of autonomy in pediatrics under the new Civil and Commercial \\ Code of the Nation. A communication of the Subcommittee on Clinical Ethics
}

\author{
Subcomisión de Ética Clínica. Sociedad Argentina de Pediatría
}

Subcomisión de Ética Clínica: Dr. Miguel A. Del Valle, Dra. Lidia Albano, Abg. Alejandro Barceló, Dra. Diana Cohen Agrest, Dra. Patricia Cudeiro, Dra. María M. Cuneo, Dra. Fernanda Ledesma, Dra. María del Carmen Martínez Perea, Dra. María C. Orsi, Dr. Gonzalo Pérez Marc, Dr. Santiago Repetto y Dr. Jorge Selandari

\section{RESUMEN}

Desde los orígenes de la Bioética, la autonomía, o sea, la capacidad de decidir por sí mismo luego de contar con el grado demadurez, la información adecuada y la ausencia de coerción, ha sido uno de sus pilares. El nuevo Código Civil y Comercial de la Nación trae importantes modificaciones, actualizaciones e incorporaciones de normas que influyen directamente en temas relacionados con el derecho a la salud y que reafirman el concepto de los niños/as y adolescentes como sujetos de derecho y ponen énfasis en el de autonomía progresiva. Es por ello por lo que consideramos importante el conocimiento de estos aspectos para los pediatras, ya que tienen implicancias en la práctica ante la toma de decisiones.

Palabras clave: bioética, autonomía personal, Código Civil, derechos del niño.

\section{ABSTRACT \\ Autonomy, understood as the power of self-decision by having full acknowledgement and free will, has been one of the pillars of Bioethics since its beginnings. The new National Civil and Commercial Code brings major changes and updates as well as additions, all of which have great implications in the practice of health rights. This whole makes a strong mark in the participation of children and adolescents as subjects of law. It is important to bring this new understanding to our attention as pediatricians, as it will involve the resolution of the daily medical practice. \\ Key words: bioethics, personal autonomy, Civil Code, children rights.}

http:/ /dx.doi.org/10.5546/aap.2016.485

Correspondencia:

Dr. Miguel A. Del Valle, mdelvalle@intramed.net

Financiamiento: Ninguno.

Conflicto de intereses: Ninguno que declarar.

Recibido: 9-5-2016

Aceptado: 6-6-2016

\section{ANTECEDENTES}

La autonomía ha sido uno de los pilares de la bioética desde sus orígenes. Es el derecho que tiene todo ser humano a decidir acerca de las acciones que se realicen sobre su propio cuerpo, sobre la base de sus valores. Para ejercer este derecho, es necesario haber alcanzado el grado de madurez suficiente para tomar decisiones por sí mismo, sin estar bajo ningún tipo de coerción y contando con la información adecuada. Este principio, fundamental y claramente comprendido en los adultos, reviste, sin embargo, aspectos no tan claros durante la edad pediátrica. De allí que puedan surgir diversos dilemas e interrogantes: ¿desde cuándo, cómo y hasta dónde un niño/a y/o adolescente se encuentra en condiciones de decidir por sí mismo? ¿Cuál es el rol de los padres y/o tutores frente a estas tomas de decisiones? ¿Cómo debería ser el accionar médico ante ellas?

Estas son las preguntas que, habitualmente, generan, en el ámbito de la pediatría, dudas de cómo debería ser nuestro accionar, ya no solo ante situaciones límites, sino también en situaciones de la práctica diaria.

Hay que reconocer, sin embargo, que la Declaración de los Derechos del Niño (1959), ${ }^{1}$ la Carta Europea de los Derechos de los Niños y las Niñas Hospitalizados $(1989)^{2}$ y, recientemente en Argentina, la Ley Nacional 26061 de Protección Integral de los Derechos de Niños, Niñas y Adolescentes $(2005)^{3}$ han ido delineando pautas basadas en una concepción actualizada del tema. Progresivamente, fue tomando mayor relevancia la atención al derecho que tiene el menor a ser escuchado, a tomar decisiones en cuanto a su persona y a que estas decisiones sean respetadas en función del grado de madurez alcanzado.

El nuevo Código Civil y Comercial de la Nación 
(NCCN) trae importantes modificaciones, actualizaciones e incorporaciones de normas que influyen directamente en temas relacionados con el derecho a la salud y -más específicamente- en los referentes a la capacidad de los menores de edad respecto del cuidado de su propio cuerpo y de su salud. ${ }^{4}$

En esa línea, el $\mathrm{NCCN}^{5}$ (en vigencia desde el 1 de agosto de 2015) cuenta, entre sus artículos, algunos que, a criterio de esta Subcomisión, presentan una relevancia tal respecto a la capacidad y/o competencia en la toma decisiones por parte de los niños/as y adolescentes que es necesario que los pediatras los conozcan.

La versión anterior del Código Civil y Comercial de la Nación (CCN), conocida como Código de Vélez Sarsfield, estuvo en vigencia desde 1871. No cabe duda de que, entre las ventajas de la versión nueva, está el haberla adaptado a los cambios ocurridos en nuestra sociedad durante estos últimos 145 años.

\section{Qué es un código civil}

Es un conjunto unitario, ordenado y sistematizado de normas de derecho privado, es decir, un cuerpo legal que tiene por objeto regular las relaciones civiles de las personas físicas y jurídicas, privadas o públicas.

\section{Artículos del nuevo Código Civil y Comercial de la Nación involucrados con el principio de autonomía}

A continuación, transcribimos los artículos que consideramos significativos:

\section{ARTÍCULO 25.- Menor de edad y adolescente}

Menor de edad es la persona que no ha cumplido dieciocho años. Este Código denomina adolescente a la persona menor de edad que cumplió trece años.

\section{ARTÍCULO 26.- Ejercicio de los derechos por la persona menor de edad}

La persona menor de edad ejerce sus derechos a través de sus representantes legales. No obstante, la que cuenta con edad y grado de madurez suficiente, puede ejercer por sí los actos que le son permitidos por el ordenamiento jurídico. En situaciones de conflicto de intereses con sus representantes legales, puede intervenir con asistencia letrada. La persona menor de edad tiene derecho a ser oída en todo proceso judicial que le concierne, así como a participar en las decisiones sobre su persona.

Se presume que el adolescente entre trece y dieciséis años tiene aptitud para decidir por sí respecto de aquellos tratamientos que no resultan invasivos ni comprometen su estado de salud o provocan un riesgo grave en su vida o integridad física. Si se trata de tratamientos invasivos que comprometen su estado de salud o está en riesgo la integridad o la vida, el adolescente debe prestar su consentimiento con la asistencia de sus progenitores; el conflicto entre ambos se resuelve teniendo en cuenta su interés superior, sobre la base de la opinión médica respecto a las consecuencias de la realización o no del acto médico.

A partir de los dieciséis años el adolescente es considerado como un adulto para las decisiones atinentes al cuidado de su propio cuerpo.

\section{ARTÍCULO 639.- La responsabilidad parental se}

rige por los siguientes principios:

a) el interés superior del niño;

b) la autonomía progresiva del hijo conforme a sus características psicofísicas, aptitudes y desarrollo. A mayor autonomía, disminuye la representación de los progenitores en el ejercicio de los derechos de los hijos;

c) el derecho del niño a ser oído y a que su opinión sea tenida en cuenta según su edad y grado de madurez.

\section{Análisis del contenido de los artículos precedentes}

Se considera, en el art. 25, al igual que en el Código anterior, que son menores de edad todas aquellas personas que no han cumplido los 18 años. Lo nuevo es que incorpora el concepto de adolescente y considera como tal a todo niño que supere los 13 años y hasta los 18.

El art. 26 del NCCN hace referencia a que la persona menor ejerce sus derechos a través de sus representantes (por ejemplo, sus padres). Sin embargo, incorpora el concepto de la "autonomía progresiva" al hacer referencia a que aquel menor que cuente con edad y grado de madurez suficiente puede ejercer por sí mismo los actos que le son permitidos por el ordenamiento. Igualmente, puede contar con su propia asistencia letrada en caso de conflicto de intereses con sus representantes.

Sobre la base de los Derechos del Niño, así como de la Ley de Protección Integral de los Derechos de Niños, Niñas y Adolescentes, se reconoce a los niños/as y adolescentes -en forma expresa- el derecho a ser oídos en juicio y a participar en las decisiones sobre su persona.

Se podría afirmar que al adolescente se le reconocen ciertas aptitudes, en particular las relacionadas con los derechos personalísimos (derechos que están unidos íntimamente a la persona: a la salud, intimidad, imagen, honor, 
etc.), ya que, a partir de esa condición, se presumen ciertas competencias relacionadas con decisiones privativas de su persona.

El NCCN, a diferencia del anterior (que fijaba la edad de discernimiento a los 14 años y en el que solo las personas mayores de edad podían dar su consentimiento para actos médicos), presume que el adolescente entre los 13 y los 16 años estaría en situación de poder decidir sobre determinados actos médicos y lo equipara, a partir de los 16 años, a un adulto en cuanto a las decisiones sobre su propio cuerpo. Se presume que el adolescente de entre 13 y 16 años es apto para decidir por sí mismo respecto de aquellos tratamientos que no resulten invasivos ni comprometan su estado de salud o provoquen un riesgo grave para su vida o su integridad física. Si se tratara de tratamientos invasivos que comprometieran su estado de salud o pusieran en riesgo su integridad o su vida misma, el adolescente debe prestar su consentimiento con la asistencia de sus progenitores. El conflicto entre ambos se resolvería teniendo en cuenta su interés superior, sobre la base de la opinión médica respecto de las consecuencias de la realización o no del acto médico.

A partir de los 16 años, el adolescente es considerado como un adulto para las decisiones atinentes al cuidado de su propio cuerpo. Con respecto al concepto de responsabilidad parental, se entiende que los niños no deben ser considerados objeto de protección, sino sujetos de pleno derecho; deben recibir protección integral y gozar de todos los derechos que tienen las personas adultas, además de un grupo de derechos específicos que se les otorga por la particularidad de que los niños se encuentran en desarrollo. Así, la responsabilidad parental se entiende como una función y acompañamiento que los progenitores ejercen en interés de los hijos y deben asistirlos en la incorporación de competencias propias de las distintas etapas de desarrollo. ${ }^{6}$ Esta debe ser ejercida en el marco del respeto por el interés superior del niño, la autonomía progresiva del hijo conforme a sus características psicofísicas, aptitudes y desarrollo, y el derecho del niño a ser oído y a que su opinión sea tenida en cuenta según su edad y grado de madurez.

En resumen, debería considerarse que la representación de los padres en el ejercicio de los derechos de sus hijos, en el caso de derechos personalísimos, va disminuyendo en función de la autonomía progresiva que estos pueden ir adquiriendo.

\section{Aplicación del Código en la práctica}

1. Al igual que en el Código anterior, para la Ley, se deja de ser menor a partir de los
18 años, momento en que se adquieren todas las capacidades del adulto.

2. Se incorpora el concepto de adolescente a partir de los 13 años, basado en el principio de autonomía progresiva.

3. Antes de esa edad (menor de 13 años), para cualquier toma de decisiones médicas, es necesario el consentimiento de padres y/o tutores, de acuerdo con cada caso.

4. Independientemente de la edad, es necesario que el niño/a reciba la información necesaria de acuerdo con su grado de entendimiento.

5. Se deberá considerar, desde un enfoque bioético, que la competencia o grado de madurez no depende solamente de aspectos cronológicos. Esto significa que no siempre la capacidad (visión jurídica) coincide con la competencia (madurez), por lo que la competencia para tomar decisiones podría adquirirse aún por debajo de los 13 años de edad. En ese caso, y de acuerdo con las circunstancias, la opinión del menor de edad deberá ser tenida en cuenta en relación con su racionalidad y aún en diferencia con la de sus padres. En caso de disenso, una vez agotadas todas las instancias de negociación entre el niño/a y sus padres/tutor/es, deberá considerarse la intervención del Comité de Bioética y -como último y no deseable recurso- la intervención legal.,8

6. Al evaluar cada caso, se deberá considerar, respecto de las presunciones, que las mismas pueden verse desvirtuadas por la realidad que se presenta al tratar al paciente en cuestión; por otro lado, la evaluación que debe realizarse para determinar la competencia desde el punto de vista bioético no resulta tan estricta como aquella que debe emplearse a los fines de determinar la capacidad civil. ${ }^{7}$

7. A partir de los 13 años, se presume la capacidad de toma de decisiones, por lo que es el adolescente el que consiente, con o sin el acompañamiento de los padres y de acuerdo con las circunstancias. Es aquí cuando comienzan las distintas interpretaciones y controversias. Como otros, advertimos claras dificultades prácticas al materializar tal distinción:

a) Se hace referencia a los tratamientos y se interpreta que se ha querido hacer referencia a todo acto médico. Si no fuese así, quedarían excluidos, por ejemplo, todos los métodos diagnósticos.

b) La contraposición del concepto de tratamiento "no invasivo o no riesgoso" al de "invasivo o riesgoso" amerita distintas interpretaciones, ya que algo que puede 
parecer inofensivo (o no invasivo) para ciertas personas puede no serlo para otras.

c) Se deberá tener en cuenta que, así como existen tratamientos no invasivos cuyo rechazo podría afectar la salud (como, por ejemplo, el uso de anteojos), existen, a su vez, actos médicos invasivos que no necesariamente la comprometen (ej.: sondaje vesical).

Por lo tanto, se deberá observar con cautela la distinción entre los conceptos de tratamiento médico invasivo o riesgoso y aquellos que no lo son. ${ }^{9}$ En este sentido, hay quienes, incluso, consideran que no debería hacerse referencia a tratamientos invasivos o no invasivos, sino considerar la gravedad de la decisión y no de diferencias en la toma de decisiones, conforme el método sea invasivo o no invasivo. ${ }^{10}$

8. A partir de los 16 años, el adolescente es considerado como un adulto para las decisiones atinentes al cuidado de su propio cuerpo, lo que significa que puede decidir por sí mismo, independientemente de la decisión de sus padres. Este punto es uno de los que más controversia han generado, tanto en el ámbito jurídico como en el médico. Tal es la controversia que algunos han planteado que se ha legislado en forma confusa y peligrosa, y se ha habilitado a adolescentes mayores de 16 años a asumir decisiones autónomamente al considerarlos como adultos para las decisiones atinentes al cuidado de su propio cuerpo. En este aspecto, quizás hubiera resultado más prolijo decir que gozaban de capacidad de ejercicio para dichos actos, si lo que se pretendía era liberarlos de la categoría de incapaces con la que los inviste el art. $24 \mathrm{del}$ NCCN. ${ }^{9}$

En la misma línea de pensamiento, otros han considerado lo siguiente: el adolescente de la edad referida será considerado un adulto y, por lo tanto, con plena capacidad para el cuidado de su propio cuerpo, pero, ante decisiones que impliquen un sesgo de riesgo y, por lo tanto, salgan de la pauta de razonabilidad del planteo, los progenitores responsables deberán ser consultados. El profesional de la salud o quien afecte de alguna manera el cuerpo del adolescente deberá propiciar que las decisiones del joven de 16 años sean tomadas con el acompañamiento de los progenitores, pues consideramos que es en el contexto familiar donde se debería encontrar la debida orientación y contención para operar responsablemente en el cuidado del cuerpo del hijo. ${ }^{11}$

En contraposición con estas posturas, y haciendo, fundamentalmente, hincapié en la autonomía progresiva y en la capacidad de decidir de los adolescentes, algunos autores intentan presentar los posibles cruces entre el principio de autonomía progresiva y la nueva legislación civil y comercial; es decir, enumerar, sin pretensiones de agotar todas las situaciones posibles, qué actos pueden realizar las personas menores de edad: a) por sí solas, b) con el asentimiento de uno de sus progenitores, c) con el de ambos $y \mathrm{~d}$ ) en su defecto, dada la subsidiariedad de la injerencia estatal, con la intervención del Ministerio Público, de conformidad con las facultades otorgadas en el ámbito extrajudicial o judicial por el art. 103 del NCCN. ${ }^{12}$

En el citado trabajo, se plantean una serie de situaciones médicas, basándose en que tan contrario al ansiado interés superior del niño es restringir el ejercicio de ciertos derechos cuando los niños o jóvenes están en condiciones de hacerlo como permitirlos cuando todavía no lo están. ${ }^{12}$ Estas se encuentran divididas por edad y pueden ser incluidas -o no- en el marco conceptual del "cuidado de su propio cuerpo", a fin de definir aquellas que pueden ser decididas por sí mismo y aquellas que necesitan el acompañamiento de los padres y/o tutores.

En resumen, consideramos que, enfrentados a una situación médica y sin dejar de respetar el derecho que le asiste a un adolescente a partir de los 16 años para la toma de decisiones por sí mismo, se debería evaluar la gravedad de la situación, la razonabilidad de la decisión y sus implicancias, así como (de ser posible) contar con el acompañamiento de los padres. Según esto, no debería ser considerado en igual plano el rechazo a un tratamiento con escasas o nulas posibilidades de éxito o una toma de decisión respecto de la salud reproductiva que el negarse a recibir un tratamiento por parte de una adolescente afectada por un trastorno de la alimentación.

\section{CONCLUSIÓN}

A pesar de las críticas recibidas, no caben dudas de que el NCCN, sobre todo en el área de la pediatría, ha reafirmado principios elementales como el reconocimiento de los niño/as y adolescentes como sujetos de derechos, así como el concepto de autonomía progresiva en la toma de decisiones sobre el cuerpo.

En relación con el escaso tiempo de su entrada en vigencia, creemos que, a medida que vayan surgiendo los diversos dilemas, se podrán ir clarificando aquellos puntos que han generado y que aún generan dudas para su aplicación. Mientras tanto, y teniendo en cuenta que el NCCN permite interpretaciones disímiles respecto de ciertas cuestiones, creemos que se 
debería analizar cada situación en particular, así como asumir y/o acompañar aquellas decisiones que estén encuadradas tanto en el respeto por la opinión del actor como en lo que se considere el mejor interés. En este sentido, avalamos la doctrina que sostiene que una categorización como la prevista en el art. 26 del Código no debe interpretarse en forma rígida ni aplicarse a rajatabla. ${ }^{8}$

A su vez, coincidimos con lo expresado por otros en relación con la posibilidad de decidir por sí mismo: que la pauta fijada por la norma debe ser razonablemente interpretada, pues lo que no es razonable no es ajustado a derecho. ${ }^{11}$ Podríamos agregar que tampoco estaría encuadrado dentro de los principios fundantes de la bioética.

\section{REFERENCIAS}

1. Declaración de los Derechos del Niño [Internet]. [Acceso: 31 de marzo de 2016]. Disponible en: http://www. humanium.org/es/declaracion-de-los-derechos-del-ninotexto-completo/.

2. Carta Europea sobre los derechos de los niños y las niñas hospitalizados [Internet]. [Acceso: 31 de marzo de 2016]. Disponible en: http://www.neuquen.edu.ar/direcciones/ modalidad\%20hospitalaria/cartainfantshospitalitzatscast.pdf.

3. Ley N. ${ }^{\circ} 26061$. Ley de Protección Integral de los Derechos de las Niñas, Niños y Adolescentes. Buenos Aires, Argentina, 28 de septiembre de 2005. [Acceso: 31 de marzo de 2016]. Disponibleen:http://infoleg.mecon.gov.ar/infolegInternet/ anexos/110000-114999/110778/norma.htm.

4. Rodríguez MC. El impacto del Nuevo Código Civil y Comercial de la Nación en el ámbito de la Salud. Rev Hosp Niños B Aires 2015;57(256):9-12.

5. Argentina. Código Civil y Comercial de la Nación. Buenos Aires: Infojus; 2014. [Acceso: 31 de marzo de 2016]. Disponible en: http://www.saij.gob.ar/docs-f/codigo/ Codigo_Civil_y_Comercial_de_la_Nacion.pdf.
6. Cataldi MM. La noción de coparentalidad y el derecho de los hijos a vivir en familia [Internet]. [Acceso: 31 de marzo de 2016]. Disponible en: http://www.nuevocodigocivil. com/wp-content/uploads/2015/06/La-noci\%C3\%B3nde-coparentalidad-y-el-derecho-de-los-hijos-a-vivir-enfamilia-por-Myriam-M.-Cataldi.pdf.

7. Ciruzzi MS. El proceso de toma de decisiones médicas en pediatría: el rol paciente [Internet]. [Acceso: 31 de marzo de 2016]. Disponible en: http://www.unesco.org.uy/ shs/fileadmin/templates/shs/archivos/TrabajosLibresBioetica /25.\%20El\%20Proceso\%20de \%20toma $\% 20 \mathrm{de} \% 20$ decisiones.pdf.

8. Chiapero SM, Oroná WR, Fernández AP. Capacidad progresiva en niños, niñas y adolescentes [Internet]. [Acceso: 31 de marzo de 2016]. Disponible en: http:// www.pensamientocivil.com.ar/system/files/2015/10/ Doctrina2102.pdf.

9. Castro SB, Montalto AM. La capacidad de los adolescentes para disponer sobre actos en su propio cuerpo [Internet]. [Acceso: 31 de marzo de 2016]. Disponible en: http:// www.pensamientocivil.com.ar/system/files/2015/10/ Doctrina2099.pdf.

10. Abud C. ¿Qué cambia en la Salud con el nuevo Código Civil? [Internet]. Buenos Aires: Doc Salud;2016. [Acceso: 31 de marzo de 2016]. Disponible en: http:/ / www.docsalud. com/articulo/6196/qu\%C3\%A9-cambia-en-la-salud-conel-nuevo-c\%C3\%B3digo-civil.

11. Bertoldi de Fourcade MV, Stein P. Algunos aportes respecto a la capacidad del adolescente de 16 años para las decisiones relativas al cuidado de su propio cuerpo [Internet]. [Acceso: 31 de marzo de 2016]. Disponible en: http://jndcbahiablanca2015.com/wp-content/ uploads/2015/09/Bertoldi-y-otro_ALGU.pdf.

12. Kemelmajer de Carlucci A, Herrera M, Lamm E, Fernández S. El principio de autonomía progresiva en el Código Civil y Comercial. Algunas reglas para su aplicación [Internet]. [Acceso: 31 de marzo de 2016]. Disponible en: http://www.saij.gob.ar/ aida-kemelmajer-carlucci-principio-autonomiaprogresiva-codigo-civil-comercial-algunas-reglas-parasu-aplicacion-dacf150461-2015-08-18/123456789-0abcdefg1640-51fcanirtcod.

\title{
El impacto de la educación inicial en el desarrollo infantil Preschool education impact on child development
}

\author{
Documento conjunto de los Comités de Pediatría Ambulatoria, CIREDDNA y Crecimiento y Desarrollo de S.A.P. Córdoba
}

\section{Coordinadores: Dra. Cecilia Cuestas, Dr. Mario Polacov y Dra. Cecilia Vaula}

http:/ /dx.doi.org/10.5546/aap.2016.489

Correspondencia:

Dra. Cecilia Cuestas: ceci_cuestas@hotmail.com

Financiamiento: Ninguno.

Conflicto de intereses: Ninguno que declarar.

Recibido: 7-7-2016

Aceptado: 14-7-2016

\section{INTRODUCCIÓN}

Este documento surge ante la situación cada vez más frecuente de asistencia de niños menores de 4 años a salas de escolarización no formalizadas y el reciente anuncio del gobierno de la provincia de Córdoba (y del Ministerio de Educación de la Provincia) sobre la inminente reglamentación de una ley que promueve la escolarización obligatoria de los niños de 3 años (sala de 3). 